DOI: $10.5455 / 2320-1770 . \mathrm{ijr} \operatorname{cog} 000812$

Research Article

\title{
A study of benign adnexal masses
}

\author{
Jayasree Manivasakan*, Bupathy Arounassalame
}

Department of Obstetrics \& Gynecology, Sri Manakula Vinayagar Medical College and Hospital, Puducherry, India

Received: 21 November 2012

Revised: 5 December 2012

Accepted: 14 December 2012

\section{*Correspondence:}

Dr. Jayasree Manivasakan,

E-mail: drmjayasree1@yahoo.co.in

\begin{abstract}
Background: To study the relationship between age, symptoms, ultrasound findings, size and histological type of benign adnexal masses.

Methods: Clinical records were retrieved of women who had surgical management for adnexal tumors in the study period, i.e. from January 2007 to December 2010 at Sri Manakula Vinayagar Medical College and Hospital, Puducherry.

Results: There were 112 cases of ovarian tumors and tumor like lesions. 70.5\% were diagnosed as ovarian tumors, $12.5 \%$ were functional cysts, $10.7 \%$ were paraovarian and paratubal cysts, $6.25 \%$ were hemorrhagic infarct where histopathology could not be reported. The age of the patient ranged from 11 to 70 years. Most of the patients (70.5\%) presented with abdominal pain either acute or chronic. Serous cystadenoma was the most common reported ovarian tumor $(59.5 \%)$ followed by mucinous cystadenoma $(20 \%)$ and mature cystic teratoma (14\%). The cystic tumors were either functional cysts or benign tumors.

Conclusions: The commonest tumor was surface epithelial tumor. Serous cystadenoma was the most common benign tumor. Serous and mucinous tumors occurred equally on both sides. The accuracy of preoperative ultrasound was higher in dermoid cysts followed by endometriotic cysts.
\end{abstract}

Keywords: Adnexal mass, Ovarian mass, Histopathology

\section{INTRODUCTION}

Most benign and malignant ovarian masses are predominantly cystic. Differentiation of these is not always clinically apparent using either imaging tools or tumor markers. ${ }^{1}$ These cysts often require excision because of symptoms or the possibility of cancer and consequently their economic impact is significant. Ovarian cysts are best identified by transvaginal ultra sound. Larger cysts may also need to be examined by abdominal ultra sound. The management will depend upon the severity of the symptoms, the size, ultrasound characteristics of the cyst, CA 125 results, age of the patient, the risk of malignancy and her desire for further children. The objective of this study is to study the relationship between age, symptoms, ultrasound findings, size and histological type and size of ovarian tumor.

\section{METHODS}

This is a descriptive study of women who had adnexal tumors in their histopathology report from January 2007 through December2010 at Sri Manakula Vinayagar medical college and hospital, Puducherry, South India. There were One hundred and twelve cases of benign ovarian and para ovarian masses during the study period. The medical records of adnexal tumor were reviewed and information regarding age, parity, chief complaints, ultrasound and clinical diagnosis were analyzed.

\section{RESULTS}

A total of 2285 gynecological patients were admitted from January 2007 to December 2010. There were 112 cases of ovarian tumors and tumor like lesions. Seventy nine cases were benign ovarian tumors. Fourteen cases were functional cysts. Eight cases were para ovarian masses. Four cases were paratubal cysts. Seven cases were hemorrhagic infarct. The age of the patient ranged 
from 11 to 70 years. Majority of the patients presented with pain abdomen (70.5\%). Menorrhagia and dysmenorrhea were the second most common complaints.

Table 1: Symptoms.

\begin{tabular}{|c|cc|}
\hline Symptoms & Number of cases & Percentage \\
\hline Abdominal pain & 79 & 70.5 \\
\hline Abdominal mass & 7 & 6.25 \\
\hline Menorrhagia and dysmenorrhea & 13 & 11.6 \\
\hline Incidental finding & 5 & 4.6 \\
\hline Infertility & 4 & 3.57 \\
\hline Mass descending per vagina & 2 & 1.8 \\
\hline Post-menopausal bleeding & 2 & 1.8 \\
\hline
\end{tabular}

Table 2: Correlation between histopathology and USG findings.

\begin{tabular}{|ccc|}
\hline Histopathology & No. & USG report \\
\hline Corpus luteal cyst & 7 & Simple unilocular cyst \\
\hline Paraovarian cyst & 8 & Simple unilocular cyst \\
\hline Para tubal cyst & 4 & Simple unilocular cyst \\
\hline Follicular cyst & 3 & Anechoic with thin septa \\
\hline Endometriotic cyst & 4 & Simple unilocular cyst-2 \\
Cyst with internal echoes-2
\end{tabular}

*All were papillary serous cystadenomas

Table 3: Histopathology and side of tumour.

\begin{tabular}{|cccc|}
\hline Histopathology & Right side & Left side & Bilateral \\
\hline Corpus luteal cyst & 3 & 4 & 0 \\
\hline Follicular cyst & 3 & 0 & 0 \\
\hline Para ovarian cyst & 5 & 3 & 0 \\
\hline Para tubal cyst & 3 & 1 & 0 \\
\hline Serous cystadenoma & 21 & 26 & 4 \\
\hline Mucinous cystadenoma & 6 & 9 & 1 \\
\hline Dermoid cyst & 9 & 2 & 0 \\
\hline Brenner tumor & 0 & 1 & 0 \\
\hline Endometriotic cyst & 3 & 1 & 0 \\
\hline Hemorrhagic infarct & 7 & 0 & 0 \\
\hline
\end{tabular}


Table 4: Age distribution.

\begin{tabular}{|c|c|c|c|c|c|c|c|}
\hline Histopathology & \multicolumn{7}{|c|}{ Age in years } \\
\hline & $<19$ & $\mathbf{2 0 - 2 9}$ & $\mathbf{3 0 - 3 9}$ & $\mathbf{4 0 - 4 9}$ & $\mathbf{5 0 - 5 9}$ & $\mathbf{6 0 - 6 9}$ & $>\mathbf{7 0}$ \\
\hline Serous cystadenoma & 2 & 13 & 14 & 15 & 5 & 2 & 0 \\
\hline Mucinous cystadenoma & 2 & 7 & 0 & 5 & 0 & 2 & 0 \\
\hline Mature cystic teratoma & 0 & 6 & 3 & 2 & 0 & 0 & 0 \\
\hline Brenner tumor & 0 & 0 & 0 & 1 & 0 & 0 & 0 \\
\hline Follicular cyst & 0 & 2 & 1 & 0 & 0 & 0 & 0 \\
\hline Corpus luteal cyst & 0 & 2 & 4 & 0 & 1 & 0 & 0 \\
\hline Para ovarian cyst & 1 & 1 & 5 & 0 & 1 & 0 & 0 \\
\hline Paratubal cyst & 0 & 2 & 1 & 0 & 0 & 0 & 1 \\
\hline Hemorrhagic infarct & 1 & 3 & 2 & 1 & 0 & 0 & 0 \\
\hline Endometriotic cyst & 0 & 0 & 3 & 1 & 0 & 0 & 0 \\
\hline
\end{tabular}

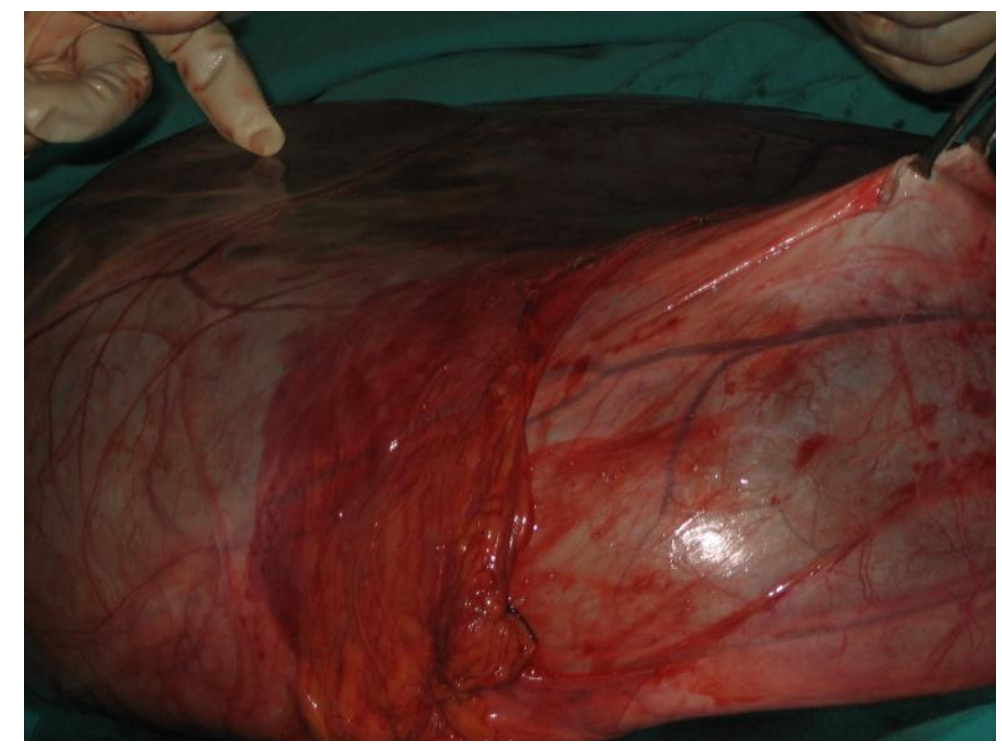

Figure 1: Large ovarian serous cystadenoma.

In pregnant patients, 3 cases were diagnosed incidentally during cesarean section, one during medical termination of pregnancy with sterilization and 1 case presented with acute abdominal pain. Two cases were post hysterectomy with functional cysts.

Forty five cases of serous cystadenoma, all cases of dermoid (10) and endometriotic cysts (4) were seen in the women $>20$ years and who haven't attained menopause.

There were 14 cases of torsion in the reproductive women, 6 in the adolescents ( $<20$ years) and 2 were postmenopausal. Out of 22 torsions, only one was reported as torsion by ultrasound and others as anechoic cysts. In histopathology, 7 were reported as hemorrhagic infarct, 3 as para ovarian cyst, 7 as serous cystadenoma, 2 as mucinous cystadenoma, 2 as para tubal cyst and 1 as multiple follicular cyst. Two patients presented with hemoperitoneum due to rupture of corpus luteal cyst.

In the postmenopausal women, out of 11 adnexal tumors 6 were reported as serous cystadenoma, 1 as paraovarian cyst, 2 as mucinous cystadenoma, 1 as corpus luteal cyst, and 1 as paratubal cyst with torsion. In 6 patients the size of the tumor was $>10 \mathrm{~cm}$.

All 6 patients in the adolescent age group presented with torsion, out of which 2 were serous cystadenoma, 2 mucinous cystadenoma, 1 paratubal cyst and 1 hemorrhagic infarct.

There were 5 cases of bilateralism, out of which 4 were serous cystadenomas and one mucinous cystadenoma. 
On comparing histopathology with ultrasound diagnosis, all corpus luteal cysts and paraovarian cysts were reported as simple unilocular cyst. Out of 4 endometriotic cysts, 2 were reported as anechoic, 2 as cyst with internal echoes. All 11 mature cystic teratomas were diagnosed as dermoid cysts. Out of 51serous cyst adenomas, 44 were reported as anechoic simple cyst, 3 with septae and 4 with echogenic foci. All mucinous cystadenomas were reported as multi septate anechoic cysts.

\section{DISCUSSION}

In the present study, the occurrence of benign adnexal tumor was almost similar between age groups more than 40 years and less than 40 years and the commonest presenting complaint was abdominal pain. These findings are comparable to the study by Kayastha. ${ }^{2}$

Surface epithelial tumor was the commonest in our study. Serous cystadenoma was found in $59.49 \%$ of cases and mucinous in $20 \%$. Surface epithelial tumors are common and that to serous cystadenoma are more common than mucinous cystadenoma in Indian studies. ${ }^{3,4}$ The prevalence of serous epithelial tumors were more in our study $82.27 \%$ compared to others $65.6 \% .^{3}$ The vast majority of benign serous tumors may not be bona fide epithelial neoplasms, but rather, may represent cystically dilated glandular inclusions (cystadenomas) and fibromas with epithelial inclusions (cystadenofibromas). ${ }^{5}$ In a study where clonality was evaluated the vast majority of serous cystadenoma was found to be polyclonal and thus supports this hypothesis. ${ }^{6}$

The occurrence of serous and mucinous was equal on both sides as noted by Vercilleni. ${ }^{7}$ Bilateralism is not a common occurrence ${ }^{8}$ and $7.84 \%$ of serous tumors were bilateral in our study.

In the study done by Lee et al, torsion was more common on the right ovary and $50 \%$ were gangrenous at laparotomy and most of the tumors were benign cystic teratomas. ${ }^{9}$ In our study, torsion was more common on the right side and $36.8 \%$ were gangrenous. In our study, 11 cases of torsion were $<10 \mathrm{~cm}$ and 11 cases were $>15 \mathrm{~cm}$. The maximum size of the tumor which underwent complete torsion was $32 \mathrm{~cm}$ in size. The highest rates of torsion are found in adnexal masses from $6-10 \mathrm{~cm}^{10}$

In our study all cases of dermoid cysts and $50 \%$ of endometriotic cysts were diagnosed by ultrasound. Kroon et al found a higher degree of correlation between ultrasound and histopathology in these tumors. ${ }^{11}$ Except mucinous cystadenoma which was multiseptate almost all adnexal tumors were reported as unilocular anechoic cyst. $^{12,13}$

In our study, the cysts ranged from $5 \mathrm{~cm}$ to $36 \mathrm{~cm}$, mostly unilocular and echo-free in the postmenopausal women and were reported as either functional cysts or benign tumors. Ekerhovd et al reported that the risk of malignancy associated with unilocular echo-free cysts was not higher than $1.6 \% .^{14}$

The limitation of the study is that this is an institution based and retrospective study, so the result obtained may or may not reflect the actual histological pattern and age distribution of ovarian tumors in Indian women.

\section{CONCLUSION}

Serous cystadenoma is the most common ovarian tumor. Abdominal pain was the commonest symptom. Serous and mucinous tumors occurred equally on both sides and bilaterality was seen in serous tumors. The accuracy of preoperative ultrasound was higher in dermoid cysts followed by endometriotic cysts. Multiseptate cysts were found to be mucinous cysts.

\section{REFERENCES}

1. Alcazar JL, Merce LT, Laparte C, Jurado M, LopezGarcia G. A new scoring system to differentiate benign from malignant adnexal masses. Am J Obstet Gynecol 2003;188:685-92.

2. Kayastha S. Study of ovarian tumours in Nepal Medical College Teaching Hospital. Nepal Med Coll J 2009;11:200-2.

3. Gupta N, Bisht D, Agarwal AK, Sharma VK. Retrospective and prospective study of ovarian tumours and tumour-like lesions: Indian J Pathol Microbiol 2007;50:525-7.

4. Pilli GS, Suneeta KP, Dhaded AV, Yenni VV. Ovarian tumours: a study of 282 cases. J Indian Med Assoc 2002;100:423-4.

5. Seidman JD, Mehrotra A.Benign ovarian serous tumors: a re-evaluation and proposed reclassification of serous "cystadenomas" and "cystadenofibromas". Gynecol Oncol 2005;96:395401.

6. Cheng EJ, Kurman RJ, Wang M, Oldt R, Wang BG, Berman DM, et al. Molecular genetic analysis of ovarian serous cystadenomas. Lab Invest 2004;84:778-84.

7. Vercillini P, Pisacreta A, Vicentini S, Stellato G, Pesole A, Crosignani PG. Lateral distribution of nonendometriotic benign ovarian cysts. BJOG 2000;107:556-8.

8. Jha R, Karki S. Histological pattern of ovarian tumours and their age distribution. Nepal Med Coll J 2008;10:81-5.

9. Lee C H, Raman S, Sivanesaratnam V. Torsion of ovarian tumors: A clinicopathological study. Int J Gynecol Obstet 1989;28:21-5.

10. Houry D, Abbott JT: ovarian torsion: a fifteen-year review; Ann Emerg Med 2001;38:156.

11. de Kroon CD, van der Sandt HA, van Houwelingen JC, Jansen FW. Sonographic assessment of nonmalignant ovariancysts: does sonohistology exist? Hum Reprod 2004;19:2138-43. 
12. Savelli L, Ghi T, De Iaco P, Ceccaroni M, Venturoli S, Cacciatore B. Paraovarian/paratubal cysts: comparison of transvaginal sonographic and pathological findings to establish diagnostic criteria. Ultrasound Obstet Gynecol 2006;28:330-4.

13. Alcazar JL, Errasti T, Minguez JA, Galan MJ, Garcia-Manero M, Ceamanos C. Sonographic features of ovarian cystadenofibromas: spectrum of findings. J ultrasound Med 2001;20:915-9.
14. Ekerhovd E, Wienerroith H, Staudach A, Granberg S. Preoperative assessment of unilocular adnexal cysts by transvaginal ultrasonography: a comparison between ultrasonographic morphologic imaging and histopathologic diagnosis. Am J Obstet Gynecol 2001;184:48-54.

DOI: $10.5455 / 2320-1770$. ijrcog000812

Cite this article as: Manivasakan $\mathrm{J}$, Arounassalame B. A study of benign adnexal masses. Int J Reprod Contracept Obstet Gynecol 2012;1:12-6. 